\title{
Praxisverkauf: Schnell schnappt die Umsatzsteuerfalle zu
}

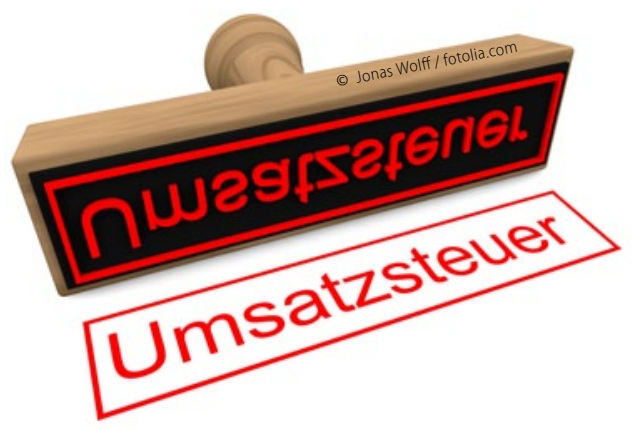

\author{
Veräußern niedergelassene Ärzte nur einen Teil ihrer Praxis - etwa weil sie selbst noch in Teilzeit \\ als Privatarzt weiterarbeiten wollen, verlangt der Fiskus zusätzlich Umsatzsteuer. Gleiches kann \\ passieren, wenn Ärzte einzelne Geräte verkaufen.
}

Da die heilberuflichen Leistungen umsatzsteuerfrei sind, gehen Ärzte meist davon aus, dass dies auch für den Verkauf ihrer Praxis oder von Praxisinventar gilt. Doch hier drohen teure Fallstricke: Nicht jeder Verkauf ist umsatzsteuerfrei. Für den Fiskus gibt es vier mögliche Konstellationen:

Fall 1: Grundsätzlich fällt beim Verkauf einer kassen- oder privatärztlichen Praxis (als sogenannte Geschäftsveräußerung im Ganzen) keine Umsatzsteuer an. Voraussetzung ist, dass der Arzt die Praxis komplett mit der Einrichtung, allen medizinischen Geräten, dem Patientenstamm sowie dem Praxiswert veräußert. Gleiches gilt, wenn ein Arzt seine komplette Einzelpraxis in eine Berufsausübungsgemeinschaft (BAG) einbringt. Scheidet er später aus der BAG wieder aus und verkauft seinen Anteil, ist dies ebenfalls umsatzsteuerfrei.

Fall 2: Anders liegt der Fall, wenn ein Arzt nur einen Teil seiner Praxis verkauft. Hier fällt die Grundlage für die Umsatzsteuerbefreiung - nämlich die Geschäftsveräußerung im Ganzen weg. Und das passiert bereits dann, wenn ein Arzt, der eine kassen- und privatärztliche Praxis führt, alters- oder krankheitsbedingt kürzer treten und nur den kassenärztlichen Praxisteil veräußern will. Wird lediglich die Privatpraxis wie bisher mit Patientenstamm, Personal und Praxisinventar fortgeführt, verlangt der Fiskus Umsatzsteuer. Ein Beispiel zeigt die finanzielle Auswirkung: Ein Arzt verkauft seine KassenPraxis und führt seine Privatpraxis wie bisher fort. Für den Praxiswert der Kassen-Praxis erhält er 60.000 Euro. Da die Praxis nicht im Ganzen veräußert wird, fällt Umsatzsteuer in Höhe von 9580 Euro an. Der Verkaufserlös wird um die zu zahlende Umsatzsteuer gemindert.

Fall 3: Beim Verkauf von Praxisinventar oder einzelnen Geräten hängt die Umsatzsteuerfreiheit wiederum von der Verwendung dieser Gegenstände ab. Nur wenn der Arzt diese Gegenstände ausschließlich für seine umsatzsteuerfreien heilberuflichen Tätigkeiten genutzt hat, fällt auch beim Verkauf keine Umsatzsteuer an. Werden Geräte jedoch teilweise für zum Beispiel steuerpflichtige Schönheits-Operationen und teilweise für steuerfreie heilberufliche Leistungen verwendet, so ist der Veräußerungserlös insgesamt umsatzsteuerpflichtig.

Fall 4: Demgegenüber ist der Verkauf des isolierten Patientenstammes oder einzelner immaterieller Wirtschaftsgüter, etwa spezieller radiologischer Software, immer umsatzsteuerpflichtig. Ob der Arzt diese Wirtschaftsgüter für umsatzsteuerpflichtige oder nur für umsatzsteuerfreie heilberufliche Leistungen verwendet hat, ist hier ohne Bedeutung, die 19 Prozent Umsatzsteuer sind immer

\section{Infobox}

\author{
Paragraf 1 Abs. 1a \\ Umsatzsteuergesetz:
}

Die Umsätze im Rahmen einer Geschäftsveräußerung an einen anderen Unternehmer (...) unterliegen nicht der Umsatzsteuer. Eine Geschäftsveräußerung liegt vor, wenn ein Unternehmen oder ein in der Gliederung eines Unternehmens gesondert geführter Betrieb im Ganzen entgeltlich oder unentgeltlich übereignet oder in eine Gesellschaft eingebracht wird.

zu zahlen. Aber: Es gibt eventuell einen Ausweg, die sogenannte Kleinunternehmerregelung. Und die dürfte zumindest bei Hausärzten in der Regel greifen - zumindest bei der Veräußerung kleinerer Praxiswerte. Denn laut der Kleinunternehmerregelung entfällt die Umsatzsteuer, wenn die steuerpflichtigen Umsätze der Praxis bzw. des Arztes im Vorjahr 17.500 Euro nicht überschritten haben und wenn sie im laufenden Jahr voraussichtlich 50.000 Euro nicht übersteigen. Bei der Berechnung zählen die umsatzsteuerbefreiten ärztlichen Heilbehandlungsleistungen nicht mit, sondern nur die umsatzsteuerpflichtigen Leistungen, wie zum Beispiel gutachterliche Tätigkeiten.

(Katja Beck)

Katja Beck ist Steuerberaterin im ETL ADVISION-Verbund; www.etl-advision.de; Ärzte Zeitung, 9.3.2013

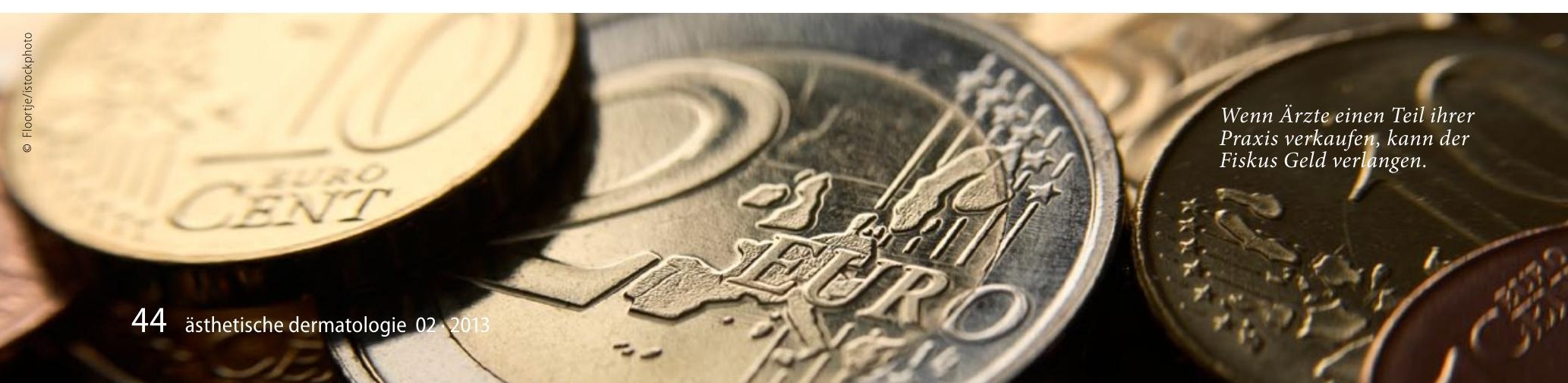

